EPiC Series in Engineering
Volume 3, 2018, Pages 892-900
HIC 2018. 13th International
Conference on Hydroinformatics

\title{
Impact of water supply on energy use and carbon dioxide in Jing-Jin-Ji region, China
}

\author{
Guohua $\mathrm{He}^{1,2}$, Yong Zhao ${ }^{1,2^{*}}$, Jianhua Wang ${ }^{1,2}$, Haihong $\mathrm{Li}^{1,2}$, \\ Yongnan $\mathrm{Zhu}^{1,2}$, and Shang Jiang ${ }^{1,2}$ \\ ${ }^{1}$ State Key Laboratory of Stimulation and Regulation of Water Cycles in River Basins, Beijing, \\ China \\ ${ }^{2}$ China Institute of Water Resources and Hydropower Research, Beijing, China. \\ heguohua010@163.com, zhaoyong@iwhr.com,wjh@iwhr.com, lihh@iwhr.com. \\ zhyn@iwhr.com, 466980875@qq.com
}

\begin{abstract}
Significant energy resources are used for water supply in Jing-Jin-Ji region with the rapid urbanization and economy increase. Yet the interrelations between water and energy have not received adequate attention in the country. In order to fill this gap, this paper performs a regional-level quantitative assessment of electricity consumption on water produce (including water extraction, desalination and recycled water reuse), as well as analyzed carbon dioxide emission caused by energy used in 2015 . The results show that total energy consumption for water supply amounts to 255.63 million $\mathrm{kWh}$ of electricity, and 0.27 million ton of carbon released in water supply progress. Due to the differences in water supply structure and water use amount, the energy consumption and carbon release of water supply in Hebei province is higher than Beijing and Tianjin city. Given increasing water supply demand, the implementation of the most stringent water management system may increase the energy consumption, and the trend of future climate change is not conducive to the conservation of water resources and energy in Jing-Jin-Ji region.
\end{abstract}

\section{Introduction}

Water and energy are inherently linked. At a basic level energy generation requires water, and water production and distribution use energy. Historically, there has been little reason to understand the nature of these links, due largely to the presumption that water was not a threat to energy security, nor electricity a threat to water security (Hamiche AM, Stambouli AB and Flazi S., 2016). This presumption is now being challenged. Increasing demand, diminishing resources, and more recently 
climate change is bringing into sharp focus the links between water and energy in unprecedented ways. As the most dynamic and development potential in northern China, the Beijing-Tianjin-Hebei region accounts for $8 \%$ of the country's population and $11 \%$ of GDP, but the available water resources account for only $1 \%$ of the country's total. And due to the long-term heavy industry-based development, the region's water pollution is also very serious. To cope with the crisis of water resources shortage, the Beijing-Tianjin-Hebei region has made extensive use of high energy intensity water sources, such as deep groundwater, inter-basin transfer water, desalinated seawater and recycled water, which has led to a significant increase in energy consumption, as well as carbon dioxide emissions during the water cycle (Li et al., 2016).

Water and energy resources provide basic services that are needed for socioeconomic development and the nexus between water and energy have become a hot topic in recent years. Current studies and research about energy for water sectors mainly focus on the processes of water cycle assessment and its water management and economic problems. Horvath and Stoke J (Horvath A and Stoke J., 2005) and Cohen et al (Cohen R et al., 2004) investigated energy consumption associated with various water supply systems in USA, which shows that although seawater desalination and reclaimed water are highly water-consuming, but the amount of water available for both water sources is reliable. Energy consumption for treatment and distribution can vary significantly for each process due to a host of geographical, water quality, and technologies (E. Orlando. LB., 2000). For example, energy intensity for water distribution in San Diego and Delhi is $0.336 \mathrm{kWh} / \mathrm{m}^{3}$ and $0.017 \mathrm{kWh} / \mathrm{m}^{3}$, while energy intensity for water treatment in these regions respectively is $0.029 \mathrm{kWh} / \mathrm{m}^{3}$ and $0.204 \mathrm{kWh} / \mathrm{m}^{3}(\mathrm{Lam}$ KL, Kenway SJ, Lant PA., 2017). There have been several studies that analyzed the impact of recycled water use on water supply structure and energy consumption. In some dry countries, recycled water consumption accounts for more than $1 \%$ of total electricity consumption. These studies have examined the relationship between water and energy from different perspectives, and are very useful in providing general quantitative results. Nevertheless, current studies and research mostly focus on energy for water related to specific water source, and data from other study areas are often used when local data are unavailable.

With the rapid economic development and the expanding of the middle class, the global demand for water is expected to grow significantly for all major water use sectors and water supply companies are working towards becoming energy neutral water in some countries including China. Although a good understanding of the water and energy interlinkages is important for integrated water and energy policy analysis and planning, study of the water-energy nexus in China is still in its infancy. To better analyze the water-energy nexus and provide new research data in Jing-Jin-Ji region of China, this paper analysis the impact of water supply on energy use and carbon dioxide in Jing-Jin-Ji region.

In this study, data from multiple sources are compiled and used to calculate energy consumption and carbon dioxide for water supply in Jing-Jin-Ji region of China. Furthermore, our work discusses the influence of increase water demand and climate change on energy consumption for water sectors in the future. A better understanding of water-energy linkages will provide valuable insights on water resource sustainable utilization and technical solutions, which, in turn, will contribute to achieving the goal of low-energy water utilization in the future.

\section{Material and methods}

\subsection{Study area}

Jing-Jin-Ji region located in the Haihe River basin, was chosen as a typical study area. Jing-Jin-Ji covers an area of $22 \times 104 \mathrm{~km}^{2}$, and its mean annual precipitation ranges from $531 \mathrm{~mm}$ to $664 \mathrm{~mm}$. This area covers Greater Beijing Economy Hub and its surrounding area, and also is the core region of the 
Bohai Bay Trade Hub, having long been the most important political, economic and cultural center of the northern China. It supports about $10 \%$ of the nation's population, food and GDP in the less than $2.5 \%$ of nation's land, which has exerted great pressure on water demand. Now water availability has been one of the main factors limiting economic sustainable development. Uncontrolled and excessive use of groundwater has caused lowering of groundwater table and intrusion of seawater, which leads to serious salinization problems particularly in the coastal areas.

\subsection{Method}

\subsubsection{Energy use for water supply}

Energy used by the water sector can be divided into constructional use and operational use. Construction use refers to the energy used in constructing water-related infrastructure such as wells, conveyance pipes and treatment plants; operational use indicates the energy used to extract, convey, treat and distribute water. The constructional use is usually counted as energy used by industry and therefore is not considered in this study. In this study, the energy use was calculated for five water sources: groundwater, surface water, inter-basin transfer water, recycled water, and desalinated water. In addition, 2015 was selected as the reference year (representing the current situation) to evaluate the energy currently consumed to supply water.

\section{- Energy use for groundwater withdrawal}

The high energy requirements for groundwater extraction are due to pumping, and vary a great deal depending on depth, type of pump, pumping efficiency, and volume of extraction. Equation (1) depicts the theoretical physical relationship between groundwater withdraw and energy use. And from Equation (1) we can clearly know that pumped volume, pumping efficiency and pumping lift are the most important factors influencing energy requirement.

$$
E=\frac{9.8 \mathrm{~N} / \mathrm{kg} \times H \times \operatorname{mass}(\mathrm{kg})}{3.6 \times 10^{6} \times P E \times(1-T D L)}
$$

Where $E$ is energy consumption ( $\mathrm{kWh}$ ); $\mathrm{H}$ is pumping lift, which is the vertical distance from inlet to outlet of pump (m); PE is pumping efficiency (\%), and TDL is energy lose rate during power supply $(\%)$.

Pumping lift is usually greater than groundwater table depth because of the continuous well fall down and head loss when pumping. It is difficult to obtain accurate pump head data for all wells. Wang et al investigated the relationship between pumping lift and groundwater table depth in 366 villages of Northern China and put forward the calculation formula (Equation (2)), which is adopted in this study. Data on groundwater table depth were compiled from observations published by China Groundwater level Yearbook for Environmental Monitoring (CGLY, 2014).

$$
H=0.906 h+21.75
$$

Where $H$ is pumping lift (m); $h$ is groundwater depth, which is the vertical distance from water table to ground $(\mathrm{m})$.

Pump efficiency is another important factor affecting the energy consumption of groundwater exploitation but has a large uncertainty due to the difference of pump station type and groundwater table. Diesel, electric and manual pumps are three major ways to pump groundwater in study area, of which only the energy required for diesel and electric pumps is considered in this article. In order to calculate the energy consumption of groundwater extraction, the following steps are taken. First, the data in the Water Resources Bulletin are statistically based on provincial. Therefore, it is necessary to take the average value of the groundwater table depth of each province in Jing-Jin-Ji. Second, it is assumed that $76 \%$ of the groundwater pumped use diesel pumps, and the remaining $24 \%$ use electric 
pumps. The pump efficiency of diesel and electricity were estimated $15 \%$ and $40 \%$, respectively. Third, energy lose rate of pump station were estimated to be $7 \%$.

\section{- Energy use for surface water pumps}

Surface water lift refers to use energy to pump surface water from rivers, lakes or reservoirs. Eq. (1) was also used to calculate energy use for surface water lift. The energy required to extract surface water varies greatly depending on pumping lift, pump efficiency, and topography. Pump efficiency and energy loss rate were assumed to be $40 \%$ and $7 \%$ for lifting surface water, respectively, which is the same as these percentages during calculations related to groundwater extraction. Pumping lift is a critical factor that influences surface energy consumption and varies according to specific local conditions. The China's Irrigation and Drainage Development Centre investigated the total surface water pumping lift in China in 2009. The pumping lift data in Jing-Jin-Ji of the CIDD Centre were used in this paper and data on the volume of surface water lift was obtained from the China Water Statistical Yearbook 2014 (CWSY, 2014).

Inter-basin water transfer projects are the most energy-intensive type of surface water supply. The energy consumption of these projects depends primarily on the length of each individual transfer project. The energy use per unit distance for surface pipe flow is a function of the material or frictional resistance of the pipe, as well as the geometry of the pipeline. A previous study calculated the energy use for pump water transfer projects per unit distance in China to be $0.0045 \mathrm{kWh} / \mathrm{m}^{3}$ per $\mathrm{km}$ and this quota is adopted in this paper. Table 1 presents detailed information on the amount of water transfer among different river basins and the average lengths of the transfer projects.

\begin{tabular}{lccccc}
\hline Source & Destination & $\begin{array}{c}\text { Quantity } \\
\left(10^{4} \mathrm{~m}^{3}\right)\end{array}$ & $\begin{array}{c}\text { Length } \\
(\mathrm{Km})\end{array}$ & Projects type & Major water receiver \\
\hline Yellow River & Haihe River basin & 1000 & 146 & Pump & Tianjin \\
Yellow River & Haihe River basin & 15000 & 398 & $\begin{array}{c}\text { Pump } \\
\text { Gravitational } \\
\text { flow }\end{array}$ & $\begin{array}{c}\text { Beijing (62\%), Tianjin } \\
(24 \%), \text { Hebei (13\%) }\end{array}$ \\
\hline
\end{tabular}

Table 1: Inter basin water transfer projects in Jing-Jin-Ji in 2015

\section{- Energy use for recycled water treatment}

The treatment of recycled water was divided into two categories for our purposes: preliminary treatment before discharging water into the environment, and high-quality treatment for water recycling. Eq. (3) was used to calculate the energy consumed to process recycled water:

$$
E=Q_{i} \times R_{W} \times(1+L)+Q_{i} \times R_{R}
$$

where $\mathrm{E}$ is energy consumption $(\mathrm{kWh})$; Qi is the volume of recycled water $\left(\mathrm{m}^{3}\right)$; $\mathrm{L}$ is water lost to pipeline leaks in the water supply system (\%), and distribution losses in the water supply network were estimated to be $15 \%$ for our purposes; and RW and RR are energy needed for treating recycled water and wastewater $\left(\mathrm{kWh} / \mathrm{m}^{3}\right)$, respectively.

\section{- Energy use for seawater desalination}

Reverse osmosis (RO) and low-temperature multiple-effect distillation (MED) are the two major types of desalination technology currently used in China, with $80.3 \%$ of desalination plants employing RO and 14.5\% adopting MED. Zheng et al. (Zheng et al., 2014) estimated that the average energy required to desalinate water using RO and low-temperature MED in China was 5 and $8 \mathrm{kWh} / \mathrm{m}^{3}$, respectively. Therefore, the weighted average value of $6.5 \mathrm{kWh} / \mathrm{m}^{3}$ was employed as the amount of energy required for desalination in this study. 


\subsubsection{Carbon dioxide for water supply}

In this study, converting method are be used to calculate carbon emissions in Jing-Jin-Ji region. The calculation formulae are given below:

$$
\begin{gathered}
E_{\text {Total }}=E_{G}+E_{S}+E_{R}+E_{\text {sea }} \\
C_{d i}=E \times C_{c o}
\end{gathered}
$$

Where $E_{\text {Total }}$ is total electricity consumption for water supply in Jing-Jin-Ji (kWh). $E_{G}, E_{S}, E_{R}, E_{S e a}$ is energy use for groundwater withdrawal, surface water pump, recycled water treatment and seawater desalination, respectively $(\mathrm{kWh}) . C_{d i}$ is carbon dioxide for water supply $(\mathrm{t})$, and $C_{C O}$ is convert coefficient for electric conversion to carbon dioxide $(\mathrm{t} / \mathrm{kWh})$. According to power type, the $C_{C O}$ value of $1.1 \mathrm{~kg} / \mathrm{kWh}$ was employed in this paper.

\section{Results}

\subsection{Current situation of water supply in Jing-Jin-Ji}

According to the China Water Resources Bulletin, Jing-Jin-Ji used about 25.1 billion $\mathrm{m}^{3}$ of water in 2015 (excluding direct seawater use). The share of water supply in study area are shown as in Fig.1. Some initial observations can be made about water supply in China in 2015. First, the majority of the water supply originated from surface water and groundwater. Recycled water and desalinated seawater combined supplied only $7 \%$ of the total freshwater used. Second, groundwater is the largest source in Jing-Jin-Ji, and met $62 \%$ of water needs. With the long-term overgrowth of groundwater, one can expect each unit of water withdrawn to require more energy, in addition to growing environmental and ecosystem impacts. Third, as a high energy intensity water source, the supply amount of inter-basin transfer water increased rapidly. In 2015, about $7 \%$ of China's inter-basin transfer water was used by Jing-Jin-Ji region.

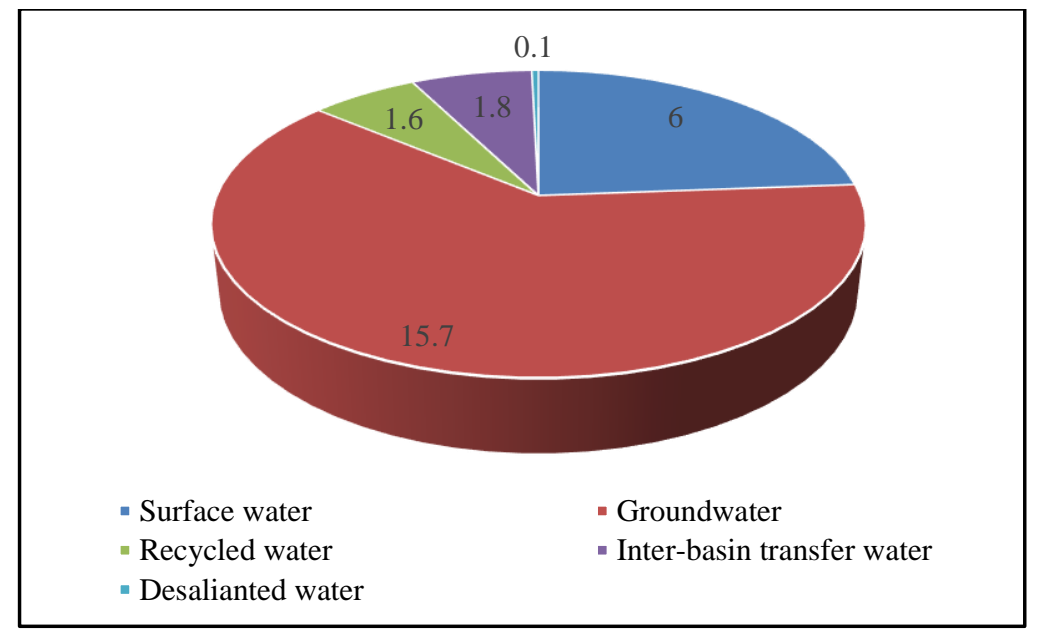

Figure 1: Water supply structure in Jing-Jin-Ji in 2015 (billion $\mathrm{m}^{3}$ ) 


\subsection{Energy use and carbon dioxide in water supply in Jing-Jin-Ji}

Fig. 2 depicts the energy required for water supply together in Jing-Jin-Ji in 2015. The chain of water supply consumed 255.63 million $\mathrm{kWh}$. The nexus between water and energy is very visible in the amount of energy used for water produce (Fig.2), which is about two thirds (65\%) of energy is consumed in groundwater pumping. Followed by surface water and recycled water, respectively contributed to $28 \%$ and $5 \%$ to water-related energy. From another point of view, the energy consumption varies greatly among different water users. It can be seen in Fig. 2 that $60 \%$ of the energy is consumed by agriculture, in which groundwater pumping contributing the majority (81\%).

The spatial distributions of provincial electricity use for water supply are also shown in Fig.3. Different climatic conditions and economic development patterns have led to the differences in water use structure, and various water use structures have resulted in different energy consumption patterns for water production. Energy use for groundwater extraction is mainly concentrated in Jing-Jin-Ji due to the high proportion of groundwater use in those area. Especially in Hebei, energy use for groundwater pumping accounted for $85 \%$ of total. Energy use for recycled treatment has a linear relationship with the amount of wastewater discharge. At present, recycled water use in Beijing and Tianjin accounts for $23 \%$ and $10 \%$ of the total water supply respectively, but the amount of recycled water in Hebei is only $1 \%$, which indicates a great potential for development in future. Desalinated water is used only in Hebei and Tianjin, and Tianjin contribute the majority for desalinated energy use (97\%).

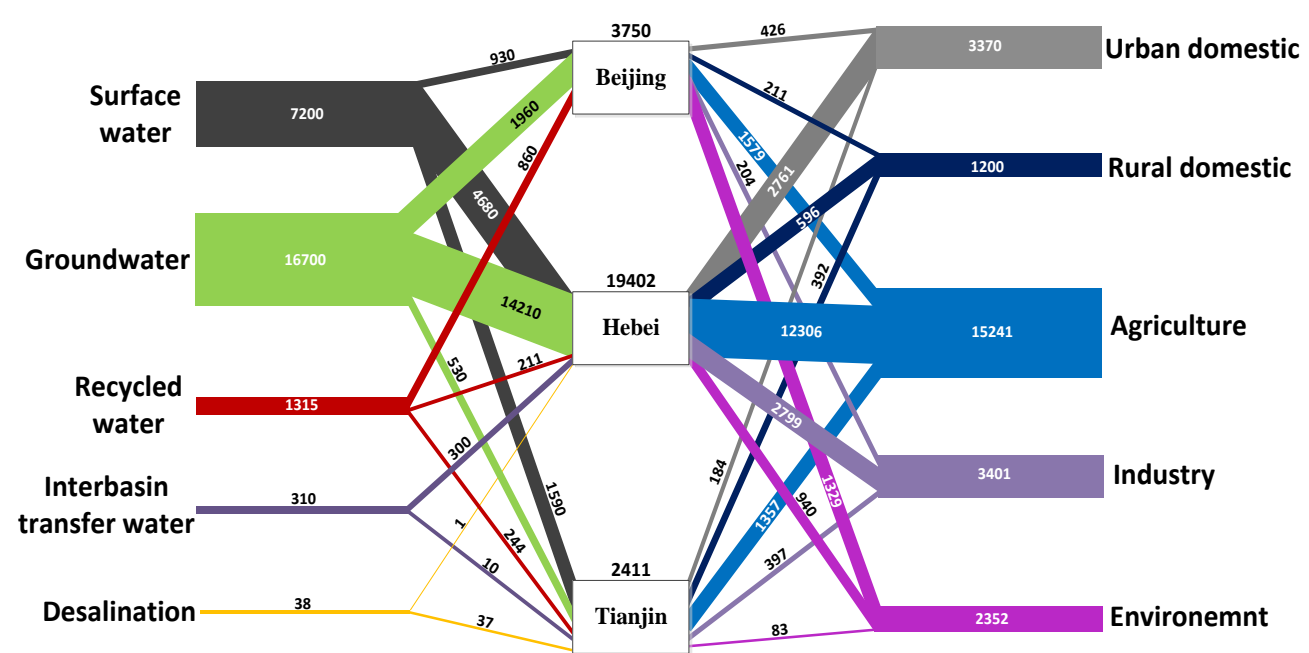

Figure 2: Energy for water produce in 2015 in Jing-Jin-Ji (104 kWh)

The carbon dioxide emissions in the progress of water supply in Jing-Jin-Ji are shown in Fig.3. In 2015, the chain of carbon dioxide released 0.27 million ton, of which the Hebei province contribute the majority (76\%), while Beijing and Tianjin city accounted for $15 \%$ and $9 \%$ of total, respectively. From the perspective of water sources, groundwater exploitation is the main reason for carbon dioxide emissions from the process of water resources supply in study area, accounting for about $66 \%$ of total emissions, and followed by surface water (29\%). Despite the production of recycled water, transfer water and desalinated water has higher energy cost than traditional water sources, however, unconventional water sources account for only $5 \%$ of the total $\mathrm{CO} 2$ emissions in Jing-Jin-Ji region due to the small amount of water used. 


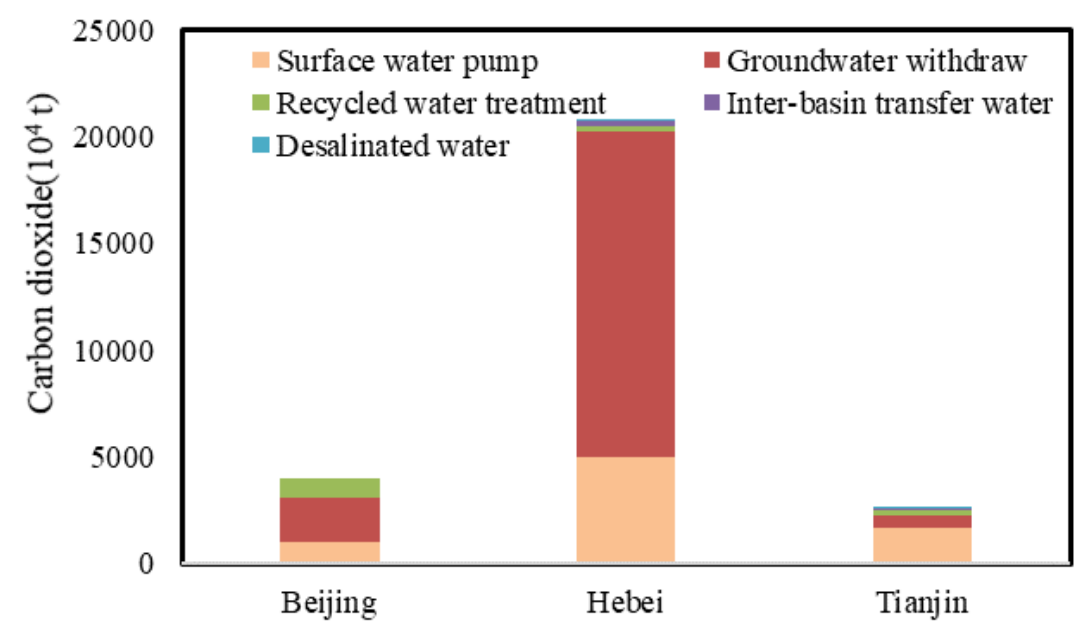

Figure 3: Carbon dioxide in water supply

\section{Discussion}

\subsection{The impact of "three red line" policy on energy use for water produce}

Since the reform and opening up, China has maintained an annual GDP increase of about $10 \%$ during past 30 years, but the extensive, fast economic growth driven by production expansion entailed massive water consumption. From 2004 to 2014, China's water consumption increased from $554.8 \mathrm{~km}^{3}$ to $609.5 \mathrm{~km}^{3}$, increased by $10 \%$. In order to ensure the sustainable use of water resources, the Chinese central government published the "opinions of the State Council on the implementation of the Most Stringent Water Resources Management" in 2012, which set mandatory targets (also known as the three red lines) for national water use, water use efficiency and water pollution control by 2020 . According to the targets, the upper limit of total water use is $670 \mathrm{~km}^{3}$ by 2020 , and the effective utilization coefficient of irrigation water, which is the ratio of water used by crops to the total irrigated water during an irrigation event, must be improved from the current 0.5 to 0.55 . To complete the water use target in 2020, the State Council has decomposed the national water use upper limit of $670 \mathrm{~km}^{3}$ into each province. Based on the amount of water used in 2015, there were a total of 30.6 billion $\mathrm{m}^{3} \mathrm{of}$ available fresh water in Jing-Jin-Ji can be consumed by 2020.

In order to meet the water demand of economic development within the scope of water use target, increase the use of recycled water and desalination will likely become a reliable alternative for the future. According to the national integrated water resources planning and 13th Five-Year national seawater utilization planning, the amount of recycle water and desalinated water will reach $2 \mathrm{~km}^{3}$ and $0.1 \mathrm{~km}^{3}$. This means that the energy consumption of recycle water treatment and desalinated water produce in 2020 will reach 18.4 million $\mathrm{kWh}$ and 4 million $\mathrm{kWh}$, an increase of 1.4 and 1.3 times over 2015. Therefore, although the most stringent water resources management system limiting the supply of freshwater and then reduces the energy use of water extraction, but the extensive use of nontraditional water will increase the energy consumption in the future. 


\subsection{Energy use for water produce under the background of climate change}

Climate is an important factor which influences energy consumption in water production. Many studies have analyzed China's future climate change through climate change models, although the forecast results vary widely, but these papers generally believe that the future precipitation in NorthChina will be further reduced, which likely increase the energy consumption of water sectors in the north. In addition to longer-term climate patterns, energy intensities of water produce are subject to the influence of short-term climate extremes such as drought. On the one hand, drought increases water consumption and then increases energy use of water produce; on the other hand, drought reduces the storage capacity of the reservoir, thereby reducing the amount of electricity generated by the hydropower station. Another important issue is that cities are facing the possibility of future rainwater increase. At present, Jing-Jin-Ji has not yet achieved the pipeline separation of rainwater and wastewater. So, the increase of urban precipitation means an increase in the amount of wastewater treatment, which also means more energy consumption.

\section{Conclusion}

In this work, we collected and complied data from multiple sources to calculate the energy consumption in Jing-Jin-Ji region for groundwater withdraw, surface water lift, recycled water treatment and desalination. Spatial distribution of energy use by different water sources were also analyzed at the regional level. Based on our calculation, electricity use of water supply in 2015 is 255.63 million $\mathrm{kWh}$, and 0.27 million ton of carbon dioxide is released with the consumption of energy use. Due to the different of water supply structure, the energy consumption of water produce varies greatly in different regions of Jing-Jin-Ji, of which the energy consumption in Hebei consumes the highest proportion of energy with the value of $76 \%$, in which groundwater pumping contributing the majority $(73 \%)$

It is essential to consider not only the availability of water use but also the energy consumption and greenhouse-gas emissions of different water use structure in order to establish a sustainable, low-carbon water produce. Water conservations strategies are effective ways to save energy. But faced with the increase of water demand, although water conservation strategies can effectively reduce fresh water use, but energy use for nontraditional water production will significantly increase in the future. Climate is another important factor influencing water supply and consumption. In the future, the precipitation in north China likely scarcer and this trend is not conducive to reducing water and energy consumption.

This study only focused on the direct energy use for water produce; however, it is equally important to explore the water use for energy production. With the rapid increase of population and economic development in China, there is no doubt that understanding the water-energy nexus is important for China's future, and it is necessary to encourage international collaboration drawn from sustainable experiences in other parts of the world.

\section{Acknowledgement}

This work was supported by the National key Research and Development Program of China [Grant No. 2016YFC0401407]; the National Science Fund for Distinguished Young Scholars [Grant No. 51625904]; and the International Science \& Technology Cooperation Program of China [Grant No. 2016YFE0102400]. 


\section{References}

CGLY. Renovation plan of Large-scale Irrigation and Drainage Pumping Station in China. 2014.

Cohen R, Nelson B, Nelson B, Wolff G, Wolff G. Energy down the drain: The Hidden Costs of California's Water Supply, 2004, 209: 263.

E Orlando LB. Methodology for analysis of the energy intensity of california's water systems and an assessment of multiple potential benefits through integrated water-energy efficiency measures. Ernest Orlando Lawrence Berkeley Larboratory, California Institute for energy efficiency, 2000.

Hamiche AM, Stambouli AB, Flazi S. A review of the water-energy nexus. Renewable \& Sustainable Energy Reviews, 2016, 65: 319-331.

Horvath A, Stoke J. Life-Cycle Assessment of Alternative Water Supply Systems in CaliforniaFinal Project Report. University of California, Berkeley Department of Civil and Environmental Engineering, 2005.

Lam KL, Kenway SJ, Lant PA. Energy use for water provision in cities. J CLEAN PROD, 2017. 143: 699-709.

Li X, Liu J, Zheng C, et al. Energy for water utilization in China and policy implications for integrated planning. International Journal of Water Resources Development. 2016, 32: 477-494.

Zheng X, Chen D, Wang Q, et al. Seawater desalination in China: Retrospect and prospect. CHEM ENG J. 2014, 242: 404-413. 